Original article

Section: Nutritional Research

\title{
Expression Profile of Brain Aging and Metabolic Function are Altered by Resveratrol or $\alpha$-Ketoglutarate Supplementation in Rats Fed a High-Fat Diet
}

\author{
Paulina Szczurek-Janicka ${ }^{1, *} \odot$, Katarzyna Ropka-Molik ${ }^{2} \odot$, Maria Oczkowicz $^{2} \odot$, \\ Sylwia Orczewska-Dudek ${ }^{1}$, Mariusz Pietras ${ }^{1}{ }^{\oplus}$, Marek Pieszka $^{1}(\bullet$ \\ ${ }^{1}$ Department of Animal Nutrition and Feed Sciences, National Research Institute of Animal Production, \\ Krakowska Str. 1, 32-083 Balice, Poland \\ ${ }^{2}$ Department of Animal Molecular Biology, National Research Institute of Animal Production, \\ Krakowska Str. 1, 32-083 Balice, Poland
}

Key words: $\alpha$-ketoglutarate, brain aging, gene expression profiling, high-fat diet, resveratrol, rats

The aim of this study was to examine the impact of different dietary interventions started at middle age on the metabolic phenotype and gene expression profiling in the hypothalamus. One-year old rats were fed either a control diet, high-fat diet (HFD), HFD supplemented with resveratrol (HFD+RESV), or HFD supplemented with $\alpha$-ketoglutarate (HFD+AKG). A 6-week HFD feeding led to significant changes in concentrations of plasma glucose, insulin, lipids, and thyroid hormones. Moreover, $32 \%$ of the 84 analyzed genes correlated with aging were differentially expressed compared to the control group, with the largest functional class being related to inflammatory response. Dietary RESV ameliorated the changes in plasma glucose, total cholesterol, and triiodothyronine concentrations induced by HFD feeding and significantly downregulated $60 \%$ of the surveyed genes compared to the control group, resulting in a major molecular shift compared to HFD alone. In contrast, AKG supplementation did not affect the metabolic phenotype, but prevented the gene expression pattern caused by HFD consumption, mimicking the effects observed in the control group. HFD feeding induces metabolic dysfunction and age-related genetic alterations in the hypothalamus of middle-aged rats, while dietary RESV or AKG may partially retard these effects, even though these compounds act in a different and specific manner.

\section{ABBREVIATIONS}

AKG - $\alpha$-ketoglutarate, AUC - area under the curve, BW - body weight, HDL - high-density lipoproteins, HFD - high-fat diet, LDL - low-density lipoproteins, NPY - neuropeptide Y, RESV - resveratrol, rT3 - reverse triiodothyronine, SD - standard deviation, T3 - triiodothyronine, T4 - thyroxine, TG - triacylglycerols.

\section{INTRODUCTION}

Aging is a complex and still poorly understood process, even in the light of its great importance and ubiquity. Studies in diverse species showed that both environmental, genetic, as well as dietary alterations might have profound effects on aging, while the most effective way to extend lifespan and delay the onset of age-associated phenotypes is caloric restriction (CR) [Baur et al., 2006; Dacks et al., 2013]. Efforts have been made to identify natural or synthetic compounds that mimic its action but without dietary sacrifice.
One of the most popular CR mimetics is resveratrol (RESV), a natural polyphenol known for its anti-inflammatory, anticancer, cardioprotective, neuroprotective, and antioxidant properties [Baur et al., 2006; Testa et al., 2014]. Although its effect on lifespan varies among species, it has been demonstrated to protect against certain age-related pathologies, including metabolic deficits and cognitive decline [Barger et al., 2008; Testa et al., 2014]. Unfortunately, in humans and other mammals, RESV features a relatively low bioavailability [Walle et al., 2004].

$\alpha$-Ketoglutarate (AKG), a key intermediate of the Krebs cycle and a keto acid providing carbon backbone for glutamate and glutamine, seems to be another interesting antiaging compound. It has been shown that AKG may prolong the lifespan of model organisms and delay the onset of multiple hallmarks of aging [Chin et al., 2014; Radzki et al., 2009]. The AKG-induced longevity effect is mediated by the regulation of cellular energy metabolism involving ATP synthase and mTOR kinase [Chin et al., 2014]. Indeed, elevated concentration of $\mathrm{AKG}$ has been also reported during

\footnotetext{
* Corresponding Author:

E-mail: paulina.szczurek@iz.edu.pl (P. Szczurek-Janicka)
} 
fasting and CR [Chin et al., 2014]. Moreover, AKG inhibits the production of oxygen radicals and thus may prevent neurons from oxidative stress and lipid peroxidation [Niemiec et al., 2011; Thomas et al., 2015]. There are also indications that intermediates of the Krebs cycle, including AKG, may affect the rate of aging at the epigenetic level through DNA methylation and histone modification [Salminen et al., 2014]. The major site of catabolism of orally administrated AKG is the small intestine, with the AKG half-life being usually short due to the rapid metabolism in enterocytes and the liver [Dąbek et al., 2005].

On the other hand, increasing evidence demonstrates a direct link between high-fat diet (HFD) consumption and metabolic dysfunction, which favors pathological brain aging and cognitive decline [Uranga et al., 2010]. Perturbation in metabolism, such as high fasting glucose, insulin resistance, hypertension, elevated adiposity or lipolysis rate, may exacerbate oxidative stress and inflammation in the brain, and thus modulate hippocampal synaptic plasticity and impair learning and memory functions [Uranga et al., 2010]. Systemic metabolic complications caused by HFD feeding lead to a pre-diabetic phenotype and obesity, current threats of public health, and furthermore, obesity has been correlated with more severe brain atrophy [Lizarbe et al., 2019; Uranga et al., 2010]. Taking into account the growing number of older people, understanding the possible link between dietary factors, metabolic response, and the rate of aging is of particular importance.

During aging, the brain undergoes numerous changes at the molecular, cellular, and structural levels. Even though the causes of brain aging remain mostly unknown, it seems that temporal patterns of gene expression might serve as biomarkers of aging. Moreover, hormonal shifts induced by changes in nutrient availability might have a profound effect on age-related transcriptional profiles [Anderson \& Weindruch, 2010]. As metabolism is largely regulated by the hypothalamus, understanding the effects of aging on its physiology may provide valuable information on aging itself. Importantly, the hypothalamic gene expression appears to be required for some protective responses to $\mathrm{CR}$ [Barger et al., 2008].

Because gene expression profiling can be used to determine the biological age of a tissue, and because many nutrients with anti-ageing potential act in a tissue-specific manner, we hypothesized that dietary supplementation with RESV or AKG would cause a beneficial shift in the metabolism and gene expression pattern of animals fed HFD towards control animals. Thus, the present study aimed to examine the effect of different dietary interventions started at middle age on metabolic phenotype and gene expression profiling associated with aging in rat hypothalamus. The interventions included HFD, HFD supplemented with RESV, HFD supplemented with AKG, and a standard chow diet as a control. Additionally, RESV was encapsulated within a triacylglycerol matrix to increase its bioavailability in the gastrointestinal tract. A rat model has been used repeatedly to study the effects of HFD consumption or CR on human aging [Andersen et al., 2011; Franco et al., 2016].

\section{MATERIALS AND METHODS}

\section{Animals and diet}

All experimental procedures were approved by the second Local Ethical Review Committee for Animal Experiments in Cracow, Poland (approval no 1162/2015) and were performed according to the approved guidelines.

Adult 1-year old male Wistar rats $(\mathrm{n}=24)$, weighing $479 \pm 39.5 \mathrm{~g}$ at a study beginning, were purchased from the Medical University of Silesia, Katowice, Poland. Rats were housed 6 per cage and maintained under standard laboratory conditions on 12-h/12-h light/dark cycle and a temperature of $22 \pm 3^{\circ} \mathrm{C}$. All animals had access to food and water available ad libitum. After a 14-day adaption period, when all rats were fed a standard chow diet [NRC, 1995], animals were randomly assigned to one of the four intervention groups $(n=6)$ : Control group, fed a standard chow diet; HFD group, fed a high-fat diet; HFD+RESV group, fed the same high-fat diet but supplemented with resveratrol; or HFD+AKG group, fed the same high-fat diet but supplemented with $\alpha$-ketoglutarate. A high-fat diet was composed of $40 \%$ energy from lard. The composition and nutritional value of the control and high-fat diets analyzed by AOAC methods [AOAC, 2000] are presented in Table 1. The dose of trans-resveratrol (Great Forest Biomedical Ltd., Hangzhou, China) in the form of microcapsules was $660 \mathrm{mg} / \mathrm{kg}$ of feed, while the dose of AKG (Gramineer Int. AB, Lund, Sweden) was $12.8 \mathrm{~g} / \mathrm{kg}$ of feed. Animals' body weight was measured weekly. At the end of a 6-week experiment, rats were anesthetized with $\mathrm{CO}_{2}$ and euthanized by decapitation.

\section{Resveratrol encapsulation}

Resveratrol was encapsulated using a mixture of C12-C22 fatty acids in the form of triacylglycerols (TG) (Berg + Schmidt, Hamburg, Germany) and calcium sulfate (Chempur, Piekary Śląskie, Poland) [Müller et al., 2002]. The TG were dissolved in a ceramic pot in a water bath at $80^{\circ} \mathrm{C}$, and a mixture of calcium sulfate and resveratrol was added so the final volume concentration was $4 \%$, and mixed thoroughly. Resveratrol accounted for $76 \%$ of the mixture volume. After obtaining a homogeneous mixture, the solution was stirred with a ceramic stirrer until it solidified at room temperature The pot with the mixture was then placed in a refrigerator at $-20^{\circ} \mathrm{C}$ for 60 min. Finally, the mixture was ground on a laboratory mill with a $1.5 \times 1.5 \mathrm{~mm}$ mesh diameter. The encapsulated RESV was prepared once before the start of the experiment and each batch of feed containing RESV was prepared every 10 days. Before being added to the feed, RESV was stored in a refrigerator at $4^{\circ} \mathrm{C}$, protected from light.

\section{Blood biochemical analysis}

Blood samples (about $10 \mathrm{~mL}$ ) were collected during slaughter by heart puncture, transferred to tubes with lithium heparin (Equimed, Kraków, Poland), and immediately placed on ice. Plasma samples were collected after centrifugation $\left(3000 \times \mathrm{g}\right.$ for $10 \mathrm{~min}$ at $4^{\circ} \mathrm{C}$ ) and stored at $-20^{\circ} \mathrm{C}$ before further handling. Concentrations of plasma glucose, TG, total cholesterol, as well as low and high density lipoprotein cholesterol 
TABLE 1. Composition and nutritional value of standard chow (Control) and high-fat diet (HFD).

\begin{tabular}{|c|c|c|}
\hline Component (g/100 g) & Control & HFD \\
\hline Oatmeal & 18.0 & - \\
\hline Barley meal & 20.0 & - \\
\hline Wheat meal & 23.0 & - \\
\hline Wheat bran & 20.0 & - \\
\hline Rapeseed oil & 3.0 & - \\
\hline Milk powdered & 10.0 & 48.0 \\
\hline Yeast & 5.0 & - \\
\hline Premix & 1.0 & 1.0 \\
\hline Lard & - & 40.0 \\
\hline Corn starch & - & 11.0 \\
\hline \multicolumn{3}{|c|}{ Nutritional value per $1 \mathrm{~kg}$ of dry weight } \\
\hline Metabolic energy $(\mathrm{MJ} / \mathrm{kg})$ & 11.4 & 20.6 \\
\hline Total protein $(\mathrm{g})$ & 157 & 157 \\
\hline Raw fat (g) & 55.1 & 404 \\
\hline Raw fiber $(g)$ & 44.9 & - \\
\hline Raw ash (g) & 34.2 & - \\
\hline Starch $(\mathrm{g})$ & 414 & 92.5 \\
\hline Magnesium (g) & 0.07 & 0.07 \\
\hline Phosphorus (g) & 3.12 & 4.22 \\
\hline Sodium (g) & 1.14 & 2.80 \\
\hline Iron (mg) & 126 & 63.8 \\
\hline Copper (mg) & 9.69 & 8.57 \\
\hline Manganese (mg) & 50.9 & 25.0 \\
\hline Zinc (mg) & 61.2 & 107 \\
\hline Cobalt (mcg) & 123 & 53.3 \\
\hline Iodine (mcg) & 104 & 0.30 \\
\hline Selenium (mcg) & 0.36 & 0.03 \\
\hline Vitamin A (IU) & 5727 & 5192 \\
\hline Vitamin D3 (IU) & 500 & 500 \\
\hline Vitamin E (mg) & 9.67 & 11.0 \\
\hline Vitamin B1 (mg) & 6.74 & 2.32 \\
\hline Vitamin B2 (mg) & 7.78 & 11.0 \\
\hline Vitamin B6 (mg) & 6.21 & 2.75 \\
\hline Vitamin B12 (mcg) & 6.21 & 18.2 \\
\hline Vitamin C (mg) & 1.29 & - \\
\hline Vitamin K3 (mg) & 0.67 & 0.66 \\
\hline Folic acid (mg) & 1.29 & 0.48 \\
\hline Nicotinic acid (mg) & 97.9 & 12.7 \\
\hline Pantothenic acid (mg) & 23.9 & 19.7 \\
\hline Choline (mg) & 1199 & 652 \\
\hline Biotin (mg) & 0.21 & 0.16 \\
\hline
\end{tabular}

fractions (LDL/HDL) were determined with the colorimetric method using commercial kits (Cormay, Łomianki, Poland) and a Beckman DU-640 spectrophotometer (Fullerton, CA, USA), according to the manufacturer's instructions. Radioimmunological quantitation of ghrelin and leptin as well as insulin, neuropeptide Y (NPY), and thyroid hormones (T3, T4, rT4) was performed with commercial kits (Phoenix Pharmaceuticals, Burlingame, CA, USA or Merck Millipore, Burlington, MA, USA, respectively) in a gamma counter (LKB Wallac MiniGamma 1275, Mt Waverley, Australia). Additionally, the glucose level was measured weekly in a blood drop from the tail vein using a glucometer and test strips (Roche Accu-Chek Active, Basel, Switzerland).

\section{Gene expression analysis}

The hypothalamic transcriptional level of 84 genes correlated with aging was analyzed using $\mathrm{RT}^{2}$ Profiler $^{\mathrm{TM}}$ PCR Array Rat Aging system (Qiagen, Hilden, Germany, Table 2). Hypothalamus was rapidly dissected and immediately placed in an RNAlater solution (Ambion, Austin, TX, USA), incubated at $4^{\circ} \mathrm{C}$ for $24 \mathrm{~h}$, and stored at $-20^{\circ} \mathrm{C}$ until further handling. Total RNA was isolated using PureLink RNA Mini Kit (Thermo

TABLE 2. A list of genes analyzed with microarray.

\begin{tabular}{|c|c|}
\hline Biological process & Gene symbol \\
\hline Genomic instability & $\begin{array}{l}\text { BUB1B, MRPL43, POLRMT, TFAM, } \\
\text { TFB1M, TFB2M, ZMPSTE24 }\end{array}$ \\
\hline Telomere attrition & POT1, RAPIA, TERF1, TERF2, TINF2, TPP1 \\
\hline $\begin{array}{l}\text { Mitochondrial } \\
\text { dysfunction }\end{array}$ & $\begin{array}{l}\text { MRPL43, NDUFBII, POLRMT, SIRT3, } \\
\text { SIRT6, TFAM, TFBIM, TFB2M }\end{array}$ \\
\hline Proteostasis & $\begin{array}{l}\text { ARL6IP6, BUB1B, FOXO1, HSF1 (TCF5), } \\
\text { JAKMIP3, RNF144B, TXNIP, VPSI3C }\end{array}$ \\
\hline Laminopathies & LMNA, LMNB1, LMNB2, ZMPSTE24 \\
\hline $\begin{array}{l}\text { Neurodegeneration } \\
\text { \& synaptic } \\
\text { transmission }\end{array}$ & $C A L B 1, G F A P, M B P, S C N 2 B, S N A P 23$ \\
\hline Epigenetic alterations & ARIDIA, SIRT3, SIRT6 \\
\hline DNA binding & $\begin{array}{l}\text { ARID1A, ELP3, EP300, FBXL16, } \\
\text { LOC100362548, ZBTB10, ZFR, ZFP9 }\end{array}$ \\
\hline RNA binding & ELAVL1, LSM5, ZFR \\
\hline $\begin{array}{l}\text { Inflammatory } \\
\text { response }\end{array}$ &  \\
\hline Apoptosis & CASPI (ICE), CLU, EP300, PDCD6, TOLLIP \\
\hline Cellular senescence & CDKNIC (P57KIP2), RGD1564788, VWA5A \\
\hline Cell cycle & BUB1B, CDKN1C (P57KIP2) \\
\hline $\begin{array}{l}\text { Cytoskeleton } \\
\text { regulators }\end{array}$ & COL1A1, EMLI \\
\hline Oxidative stress & EP300 \\
\hline $\begin{array}{l}\text { Transcriptional } \\
\text { regulation }\end{array}$ & $\begin{array}{l}\text { ARIDIA, EP300, FOXO1, HSF1 } \\
\text { (TCF5), PHF3, SMAD2 (MADH2) }\end{array}$ \\
\hline
\end{tabular}


Fisher Scientific, Waltham, MA, USA) following the manufacturer's protocol. RNA concentration and integrity were assessed using TapeStation 2200 and RNA ScreenTape 2200 (Agilent, Santa Clara, CA, USA). The RNA Integrity Number for all samples was $>7.5$. The RNA samples were stored at $-80^{\circ} \mathrm{C}$ before further handling. The $1000 \mathrm{ng}$ of extracted RNA was reverse-transcribed using a cDNA conversion kit (RT ${ }^{2}$ First Strand Kit, Qiagen, Hilden, Germany) according to manufacturer's recommendations. The cDNA was used in the RT ${ }^{2}$ Profiler ${ }^{\mathrm{TM}}$ PCR Array Rat Aging system (Qiagen, Hilden, Germany, Cat. no. PARN-178Z) in combination with $\mathrm{RT}^{2}$ SYBR ${ }^{\circledR}$ Green qPCR Mastermix (Qiagen, Hilden, Germany, Cat. no. 330529). The plate contained primers for all analyzed genes designed by Qiagen company, as well as appropriate RNA sequences that were used as housekeeping assays and quality controls. Gene expression was determined by real-time PCR using an ABI-7500 thermocycler (Applied Biosystems, Thermo Fisher Scientific, Waltham, MA, USA) according to the manufacturer's instructions. $\mathrm{C}_{\mathrm{T}}$ values were analyzed by the data analysis web portal at http://www.qiagen.com/geneglobe with the $\mathrm{C}_{\mathrm{T}}$ cut-off set to 35 , normalized using reference genes, and $\Delta \mathrm{C}_{\mathrm{T}}$ method was used to express transcript level. Changes in gene expression were illustrated as a fold increase/decrease. The cut-off fold-change for differential expression was set as 1.5 .

\section{Statistical analysis}

Statistical significance for plasma and growth parameters was assessed using one-way ANOVA with Tukey's correction for multiple comparisons or Kruskal-Wallis test with Dunn's correction for non-Gaussian data distribution using GraphPad Prism v7 (GraphPad Software, San Diego, CA, USA). Data were expressed as mean \pm standard deviation (SD). The real-time PCR array data were statistically analyzed by the data analysis web portal at http://www.qiagen.com/ geneglobe. In all statistical analyses, differences were considered significant at $p \leq 0.05$.

\section{RESULTS AND DISCUSSION}

\section{Metabolic phenotype of rats after different dietary interventions}

Increasing evidence implicates that nutrition, and especially Western-type diet with high saturated fat content, and simultaneously low in fiber, polyphenols, vitamins, and minerals, might act like a pro-aging stimulus for many biochemical and physiological aspects of brain aging [Morrison et al., 2010; Nuthikattu et al., 2019; Uranga et al., 2010]. On the contrary, CR and its mimetics are reported to maintain metabolic function, guarantee successful brain aging, and increase lifespan in most organisms studied [Anderson \& Weindruch, 2010; Zhou et al., 2012]. However, the specific effects of different dietary interventions, regarding particularly brain aging, remain poorly understood. We used middle-aged rats to assess aging phenotypes under various dietary conditions implemented in the period before the increase in mortality. High-quality foods consumed in middle age appear to be strongly associated with better health of individuals surviving to older ages, which is critical to maintaining well-being in aging societies.

Here, as expected, a 6-week consumption of HFD composed of $40 \%$ lard (high in saturated fatty acids) resulted in alterations in carbohydrate and lipid metabolism (Figure 1). Glucose concentration was significantly $(p \leq 0.05)$ higher in HFD and HFD+AKG groups compared to the control group. Followed the increase in plasma glucose level at the end of a 6 -week study, a significantly $(p \leq 0.05)$ elevated blood glucose concentration measured weekly and expressed as area under the curve (AUC) was noted in all groups treated with HFD compared to the control rats (Figure 1). Total cholesterol level was significantly $(p \leq 0.05)$ higher in HFD and HFD+AKG groups compared to the control group. The concentrations of HDL and LDL cholesterol fractions were significantly $(p \leq 0.05)$ higher in all groups receiving HFD compared to the control group. A strong correlation between HFD and such conditions as insulin resistance, hyperglycemia, hyperinsulinemia, and hyperlipidemia, is widely known and has been repeatedly reported [Baur et al., 2006; Cho et al., 2012; Mohamed et al., 2010; Morrison et al., 2010; Nuthikattu et al., 2019; Uranga et al., 2010].

No differences were observed in the metabolic phenotype after HFD supplementation with AKG (Figure 1), which is in contrast to Radzki et al. [2009] and Tian et al. [2020], who demonstrated an improved plasma lipid profile in hypercholesterolemic rats or improved glucose tolerance in HFD-fed mice, respectively. On the contrary, HFD supplementation with RESV ameliorated the increase in plasma glucose and total cholesterol levels (Figure 1); however, the differences were not statistically significant. The antidiabetic effect of CR and RESV has been well described in the literature [Barger et al., 2008; Baur et al., 2006; Lagouge et al., 2006]. A parallel lack of RESV effect on plasma insulin (Figure 1) might suggest improved insulin sensitivity, which indeed has been demonstrated by other authors [Andersen et al., 2011; Baur et al., 2006]. Similarly, the hypocholesterolemic effect of RESV is also in the agreement with other rodent studies [Cho et al., 2012; Miura et al., 2003]. There are suggestions that RESV might inhibit hepatic 3-hydroxy-3-methylglutaryl reductase activity, a rate-limiting enzyme for cholesterol synthesis, or increase fecal bile acids excretion [Cho et al., 2012]. It should be emphasized that in our study RESV was encapsulated within a triglyceride matrix to increase its digestive stability and bioavailability after oral administration. As previously shown, RESV features low bioaccessibility and only its trace amounts reach the circulation [Walle et al., 2004].

The results of the present study also support the finding that HFD consumption results in a high circulation leptin level [Kandhare et al., 2018; Mohamed et al., 2010], although in our study a statistically significant $(p \leq 0.05)$ difference was noted only in HFD $+\mathrm{AKG}$ group compared to the control group (Figure 1). A high leptin concentration may indicate leptin resistance due to a lack of leptin receptor in the hypothalamus or abnormalities in postreceptor signaling [Jimoh et al., 2018; Mohamed et al., 2010]. A significant increase in leptin level only in the HFD+AKG group is challenging to explain and needs further investigation. Perhaps a more longterm study would reveal differences in all groups fed HFD. 
A
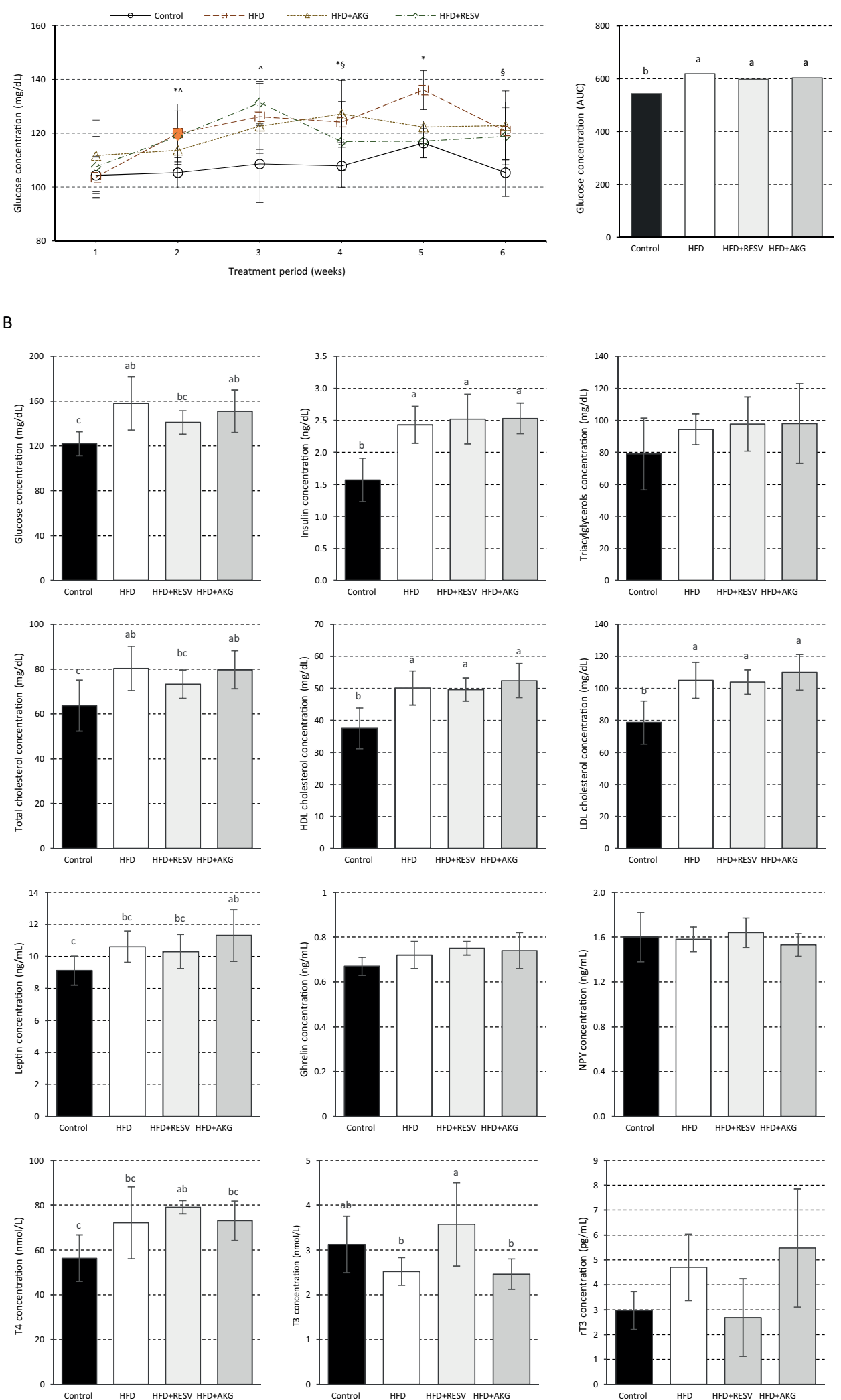

FIGURE 1. Biochemical parameters of blood plasma in rats. Middle-aged rats fed for 6 weeks with high-fat diet (HFD), HFD supplemented with resveratrol (HFD+RESV), HFD supplemented with $\alpha$-ketoglutarate (HFD+AKG) or standard feed (control group - Control).

* - indicates a significant difference between Control and HFD at $p \leq 0.05 ; \wedge$ - indicates a significant difference between Control and HFD+RESV at $p \leq 0.05 ;{ }^{\S}$ - indicates a significant difference between control and HFD +AKG at $p \leq 0.05 ;{ }^{\circ}$ - indicates a significant difference between HFD and HFD+RESV at $p \leq 0.05$. a,b - values with different superscripts differ significantly at $p \leq 0.05$.

(A) Changes in plasma glucose level during the 6-week treatment period. (B) Plasma biochemistry on the last day of the study. HDL, high density lipoproteins; LDL, low density lipoproteins; NPY, neuropeptide Y; T4, thyroxine; T3, triiodothyronine; rT3, reverse triiodothyronine. a,b,c - values with different superscripts differ significantly at $p \leq 0.05$. 
On the other hand, RESV is suggested to reverse hyperleptinemia and improve central leptin action [Franco et al., 2016; Jimoh et al., 2018]; however, our study failed to confirm such a correlation.

The present study also implicates minimal participation of ghrelin and NPY in the modulation of metabolic response to HFD under the current settings, as no significant differences were detected in their plasma concentrations (Figure 1). Nevertheless, both ghrelin and NPY are essential regulators of energy expenditure and have been previously reported to be affected by HFD [Briggs et al., 2013; Mohamed et al., 2010].

In the case of thyroid hormones, T4 was significantly $(p \leq 0.05)$ higher in the HFD+RESV group compared to the control group, while the concentration of T3 was significantly $(p \leq 0.05)$ higher only in the HFD+RESV group when compared to HFD and HFD+AKG groups (Figure 1). In contrast, there were no statistically significant differences in the concentration of rT3. It is known that euthyreosis is extremely important to control the rate and direction of metabolism. Our results indicate hypothyroidism and the conversion of T3 and/or rT3 to T4 in the animals fed HFD. A similar pattern of thyroid hormones followed HFD was noted by Mohamed et al. [2010], as well as Cheserek et al. [2016]. In the same study [Cheserek et al., 2016], HFD supplementation with RESV elevated plasma T3 to a similar level as in the group fed a low-fat diet. The observed restoration of the $\mathrm{T} 3$ level may lead to a reduction in oxidative stress since $\mathrm{T} 3$ might act as a free radical scavenger [Cheserek et al., 2016].

As it was predicted, the HFD-induced shift in metabolism had a profound effect on rats' BW gain, which was significantly $(p \leq 0.05)$ higher in HFD and HFD+RESV groups compared to the control group (Figure 2). Similarly, the final BW was higher in all groups fed HFD; however, it differed significantly only between HFD and control groups $(p \leq 0.05)$, while average water intake was significantly $(p \leq 0.05)$ lower in HFD and HFD+AKG groups compared to the control group. The obtained results are in line with other studies [Cho et al., 2012; Morrison et al., 2010]. The consumption of HFD is usually associated with an increased caloric intake and simultaneously increase in total body adiposity [Morrison et al., 2010]. Although feed intake was significantly $(p \leq 0.05)$ lower in all groups fed HFD compared to the control group, and we did not measure direct calorie intake, the energy content of a standard rat diet was substantially lower compared to HFD (Table 1). Unlike in other studies [Cho et al., 2012; Lagouge et al., 2006; Miura et al., 2003], we have not however observed the protective effect of RESV against diet-induced obesity (Figure 2). In contrast, dietary AKG suppressed HFD-induced BW gain in rats (Figure 2). Similar results after dietary AKG intake were observed in rodents fed HFD [Radzki et al., 2009; Tian et al., 2020], as well as in mice fed a basal diet [Chen et al., 2017]. It is suggested that AKG might reduce deposition of the adipose tissue, improve lipolysis and fatty
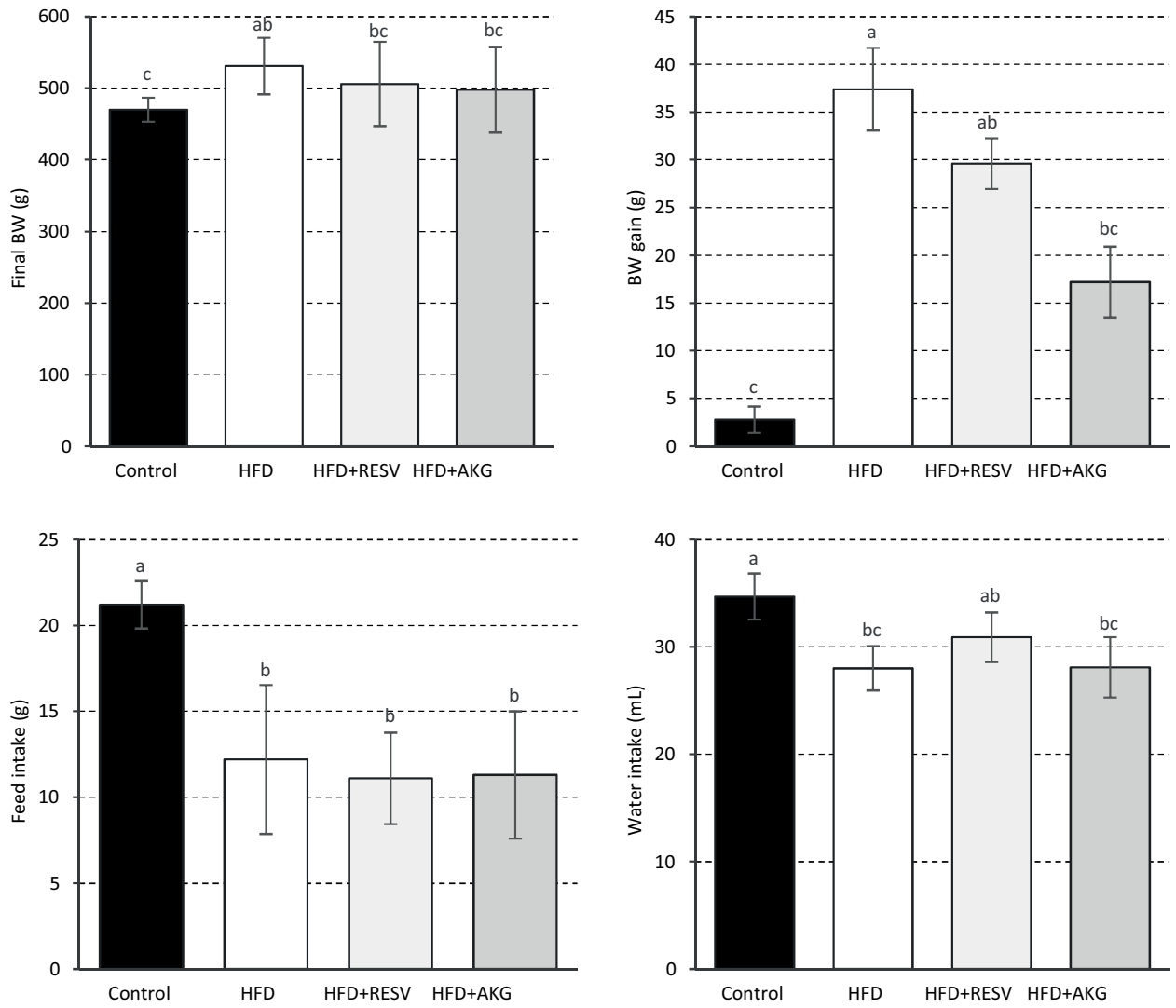

FIGURE 2. Final body weight (BW), BW gain, average daily feed intake, and water intake of rats. Middle-aged rats fed for 6 weeks with high-fat diet (HFD), HFD supplemented with resveratrol (HFD+RESV), HFD supplemented with $\alpha$-ketoglutarate (HFD+AKG) or standard feed (control group Control). a,b,c - values with different superscripts differ significantly at $p \leq 0.05$. 
acid oxidation or modify the composition of gastrointestinal microbiota [Chen et al., 2017]. It should also be noted that the HFD+AKG group was the only group with significantly elevated plasma leptin level, while leptin serves as an essential obesity indicator [Kandhare et al., 2018].

\section{Gene expression profiling}

Furthermore, to compare the age-associated gene expression profile under the different dietary interventions, the hypothalamic transcriptome of middle-aged rats was measured using the real-time PCR microarray technology. Mounting evidence indicates that alterations in the gene expression levels might have a severe impact on brain function, both at the cellular and behavioral level [Berchtold et al., 2008]. The genes involved in lifespan regulation are often associated with the metabolic signaling pathways [Fraser et al., 2005], and HFD-induced alterations in levels of energy substrates and hormones might be potent modulators of brain aging [Morrison et al., 2010]. Increased oxidative stress, and in particular protein oxidation, is suspected to mediate the effects of HFD on brain pathogenesis and cognitive decline in the elderly [Morrison et al., 2010]. Moreover, age-related cognitive disturbances are often promoted by insulin resistance, diabetes, and alterations in adipose tissue deposition [Morrison et al., 2010]. It remains unclear, however, whether dietary stressors and the resulting metabolic dysfunction accelerate the normal brain aging or initiate completely new pathological processes. Metabolic decline within the brain itself and general decreased catabolic and anabolic capacity with aging has been also reported in both human imaging studies and microarray studies with rodents [Berchtold et al., 2008].

In our study, however, HFD feeding for 6 weeks caused a moderate change in the genetic pattern of the rat hypothalamus. The significant $(p \leq 0.05)$ changes in gene expression with the fold regulation threshold of 1.5 in the rat hypothalamus are presented in Table 3 and Table 4. Of the 84 analyzed genes associated with the aging process, one gene $(\mathrm{CFH})$ was overexpressed, whereas expression levels of $26(31 \%)$ decreased in the HFD group compared to the control group. Of the downregulated genes, 35\% (9/26) might be assigned to inflammatory response, $19 \%(5 / 26)$ to transcriptional regulation, $19 \%(5 / 26)$ to proteostasis, $12 \%$ (3/26) to DNA binding, $12 \%(3 / 26)$ to neurodegeneration and synaptic transmission, and $12 \%(3 / 26)$ to laminopathies. Additionally, four genes were downregulated by more than 2-fold (FCGBP, GFAP, $L M N B 2, S C N 2 B$ ) with FCGBP being the top gene (Table 3). A non-supervised hierarchical clustering of the entire dataset to display a heat map with dendrograms indicating co-regulated genes is presented in Figure 3. The results show that group 3 (HFD $+\mathrm{AKG}$ ) is the closest to the control group. This suggests that the AKG supplementation has the potential to counteract the effects of HFD on gene expression.

Interestingly, an extensive analysis of 16 different mouse tissues showed that most of the age-related changes in gene

TABLE 3. The hypothalamic gene expression profile associated with aging - part A.

\begin{tabular}{|c|c|c|c|c|}
\hline \multirow{2}{*}{ Gene symbol } & \multirow{2}{*}{ Gene name } & \multicolumn{3}{|c|}{ Fold change $^{1}$} \\
\hline & & Control vs HFD & Control vs HFD+RESV & Control vs HFD+AKG \\
\hline $\mathrm{CFH}$ & Complement factor $\mathrm{H}$ & $1.69(p=0.0479)$ & - & - \\
\hline ANGEL2 & Angel homolog 2 (Drosophila) & - & $-2.02(p=0.0063)$ & - \\
\hline ANXA5 & Annexin A5 & - & $-1.60(p=0.0028)$ & - \\
\hline$C I Q A$ & $\begin{array}{l}\text { Complement component } 1, \mathrm{q} \\
\text { subcomponent, A chain }\end{array}$ & - & $-3.50(p=0.0008)$ & - \\
\hline$C l Q C$ & $\begin{array}{l}\text { Complement component } 1, \mathrm{q} \\
\text { subcomponent, } \mathrm{C} \text { chain }\end{array}$ & - & $-2.77(p=0.0062)$ & - \\
\hline CIS & Complement component 1 , s subcomponent & $-1.76(p=0.0422)$ & $-2.75(p=0.0102)$ & - \\
\hline$C 3$ & Complement component 3 & - & $-2.24(p=0.0085)$ & - \\
\hline$C 4 A$ & Complement component 4A (Rodgers blood group) & - & $-4.50(p=0.0001)$ & - \\
\hline$C 4 B$ & Complement component 4B (Chido blood group) & - & $-2.63(p=0.0016)$ & - \\
\hline$C 5 A R l$ & Complement component 5 a receptor 1 & - & $-1.80(p=0.0295)$ & - \\
\hline$C D 14$ & CD14 molecule & - & $-3.22(p=0.0039)$ & - \\
\hline$C X 3 C L 1$ & Chemokine (C-X3-C motif) ligand 1 & - & $-4.88(p=0.0006)$ & - \\
\hline CXCL16 & Chemokine (C-X-C motif) ligand 16 & - & $-1.83(p=0.0049)$ & - \\
\hline$F C G B P$ & Fc fragment of $\operatorname{IgG}$ binding protein & $-3.65(p<0.0001)$ & $-3.00(p=0.0003)$ & $-1.97(p=0.0008)$ \\
\hline FCGRIA & $\begin{array}{l}\text { Fc fragment of IgG, high affinity } \\
\text { Ia, receptor (CD64) }\end{array}$ & - & $-1.95(p=0.0271)$ & - \\
\hline LTF & Lactotransferrin & $-1.67(p=0.0240)$ & - & - \\
\hline PANXI & Pannexin 1 & - & $-2.63(p=0.0003)$ & - \\
\hline
\end{tabular}


TABLE 3 - continued.

\begin{tabular}{|c|c|c|c|c|}
\hline \multirow{2}{*}{ Gene symbol } & \multirow{2}{*}{ Gene name } & \multicolumn{3}{|c|}{ Fold change $^{1}$} \\
\hline & & Control vs HFD & Control vs HFD+RESV & Control vs HFD+AKG \\
\hline$T L R 2$ & Toll-like receptor 2 & - & $-1.97(p=0.0107)$ & - \\
\hline TLR4 & Toll-like receptor 4 & $-1.59(p=0.0184)$ & $-1.93(p=0.0005)$ & - \\
\hline TMEM135 & Transmembrane protein 135 & $-1.65(p=0.0003)$ & $-2.16(p=0.0049)$ & - \\
\hline TMEM33 & Transmembrane protein 33 & $-1.61(p=0.0005)$ & $-2.22(p=0.0039)$ & - \\
\hline TOLLIP & Toll interacting protein & $-1.84(p=0.0033)$ & $-3.20(p=0.0020)$ & - \\
\hline$M B P$ & Myelin basic protein & $-1.74(p=0.0127)$ & $-1.97(p=0.0076)$ & - \\
\hline GFAP & Glial fibrillary acidic protein & $-2.93(p<0.0001)$ & $-3.87(p<0.0001)$ & - \\
\hline$S C N 2 B$ & Sodium channel, voltage-gated, type II, beta & $-2.24(p=0.0006)$ & $-4.10(p<0.0001)$ & - \\
\hline PHF3 & PHD finger protein 3 & $-1.63(p=0.0010)$ & $-1.96(p=0.0066)$ & - \\
\hline SMAD2 & SMAD family member 2 & - & $-2.06(p=0.0005)$ & - \\
\hline ARIDIA & AT rich interactive domain 1A (SWI-like) & $-1.79(p=0.0025)$ & $-2.37(p=0.0077)$ & - \\
\hline EP300 & E1A binding protein $\mathrm{p} 300$ & $-1.74(p=0.0104)$ & $-2.21(p=0.0210)$ & - \\
\hline FOXO1 & Forkhead box $\mathrm{O} 1$ & $-1.60(p=0.0004)$ & $-2.01(p=0.0105)$ & - \\
\hline HSFl & Heat shock transcription factor 1 & $-1.54(p=0.0042)$ & $-1.82(p=0.0287)$ & - \\
\hline ARL6IP6 & ADP-ribosylation-like factor 6 interacting protein 6 & $-1.62(p=0.0019)$ & $-2.81(p=0.0014)$ & - \\
\hline JAKMIP3 & Janus kinase and microtubule interacting protein 3 & $-1.65(p=0.0055)$ & $-1.91(p=0.0144)$ & - \\
\hline$R N F 144 B$ & Ring finger protein 144B & - & $-2.47(p=0.0071)$ & - \\
\hline TXNIP & Thioredoxin interacting protein & $-1.50(p=0.0444)$ & $-3.22(p=0.0003)$ & - \\
\hline ELP3 & RCG52086-like & - & $-2.33(p=0.0030)$ & - \\
\hline FBXL16 & F-box and leucine-rich repeat protein 16 & - & $-3.00(p=0.0009)$ & - \\
\hline ZBTB10 & Zinc finger and BTB domain containing 10 & - & $-1.76(p=0.0086)$ & - \\
\hline ZFP9 & Zinc finger protein 9 & $-1.56(p=0.0116)$ & $-1.80(p=0.0246)$ & - \\
\hline SIRT6 & $\begin{array}{l}\text { Sirtuin (silent mating type information } \\
\text { regulation } 2 \text { homolog) } 6\end{array}$ & $-1.96(p=0.0036)$ & $-3.03(p=0.0009)$ & - \\
\hline MRPL43 & Mitochondrial ribosomal protein L43 & $-1.54(p<0.0001)$ & $-1.59(p=0.0058)$ & - \\
\hline TFAM & Transcription factor A, mitochondrial & - & $-1.50(p=0.0067)$ & - \\
\hline ZMPSTE24 & $\begin{array}{l}\text { Zinc metallopeptidase, } \\
\text { STE24 homolog (S. cerevisiae) }\end{array}$ & - & $-1.67(p=0.0227)$ & - \\
\hline$L M N A$ & Lamin A & $-1.53(p=0.0005)$ & $-1.99(p<0.0001)$ & - \\
\hline$L M N B I$ & Lamin B1 & $-1.97(p=0.0023)$ & $-2.02(p=0.0124)$ & - \\
\hline$L M N B 2$ & Lamin B2 & $-2.14(p=0.0013)$ & $-2.87(p=0.0019)$ & - \\
\hline POTI & Protection of telomeres $1 \mathrm{~A}$ & - & $-1.59(p=0.0285)$ & - \\
\hline TERF2 & Telomeric repeat binding factor 2 & $-1.78(p=0.0005)$ & $-2.45(p=0.0027)$ & - \\
\hline$T P P I$ & Tripeptidyl peptidase I & - & $-1.76(p=0.0086)$ & \\
\hline COLIAI & Collagen, type I, alpha 1 & - & $-2.54(p=0.0396)$ & - \\
\hline EMLl & Echinoderm microtubule associated protein like 1 & $-1.86(p=0.0006)$ & $-2.50(p=0.0012)$ & - \\
\hline$C D K N I C$ & Cyclin-dependent kinase inhibitor $1 \mathrm{C}$ & - & $-3.83(p=0.0010)$ & - \\
\hline
\end{tabular}

${ }^{1}$ Only genes whose expression differed significantly $(p \leq 0.05)$ with the fold regulation threshold of 1.5 are shown. Middle-aged rat fed for 6 weeks with high-fat diet (HFD), HFD supplemented with resveratrol (HFD+RESV), HFD supplemented with $\alpha$-ketoglutarate (HFD +AKG) or standard feed (control group - Control). 


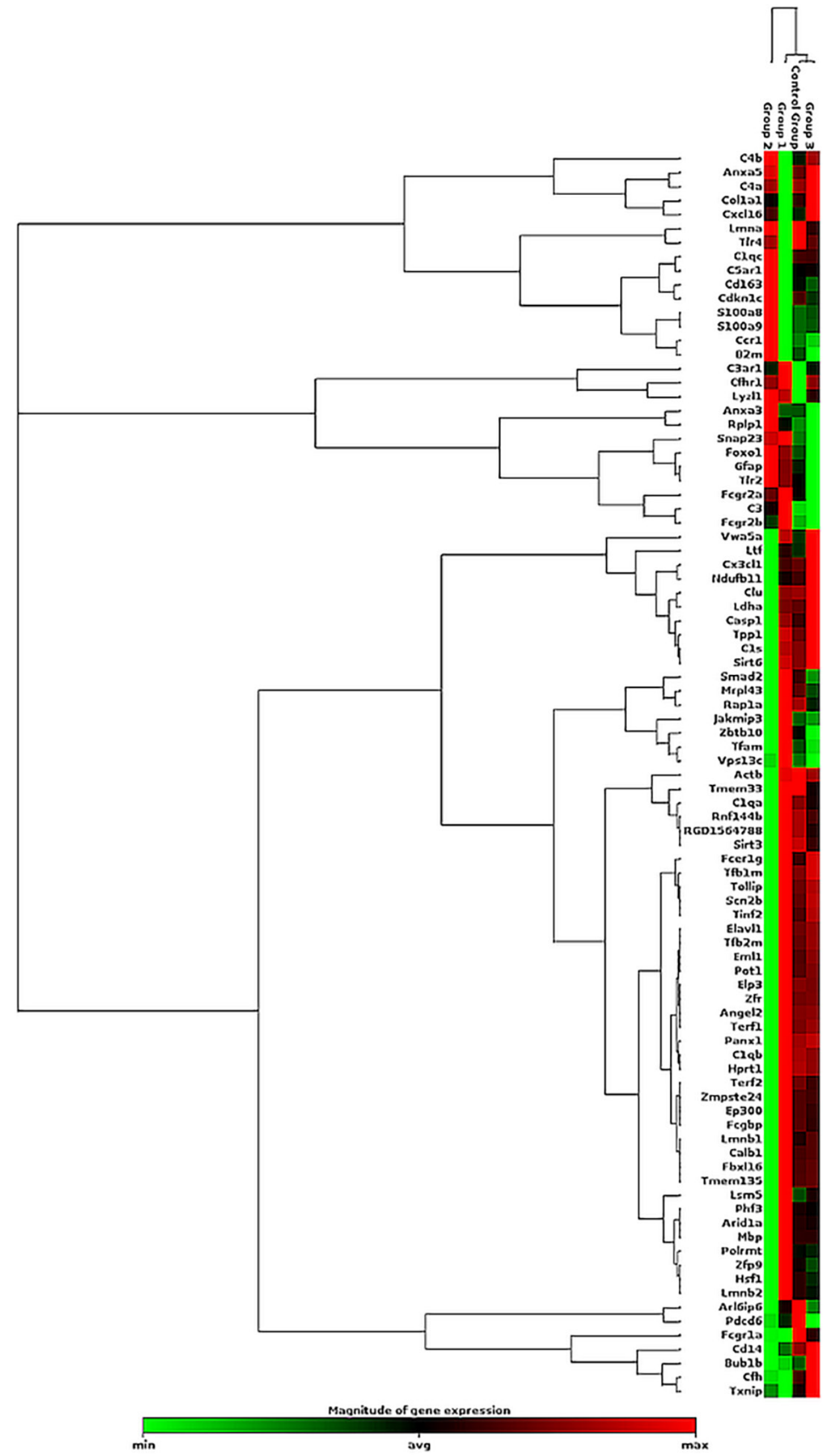

FIGURE 3. Clustergram displaying a heat map with dendrograms indicating co-regulated genes across groups. Gene expression analyzed in the hypothalamus of middle-aged rats fed for 6 weeks with high-fat diet (HFD - Group 1), HFD supplemented with resveratrol (HFD + RESV - Group 2), HFD supplemented with $\alpha$-ketoglutarate (HFD $+\mathrm{AKG}-$ Group 3) or standard feed (Control - control Group). 
expression are relatively small in magnitude (less than 2-fold) [Zahn et al., 2007]. This coincides with our results because only 4 genes displayed the fold change higher than 2 . Nevertheless, perhaps a more extended period of HFD exposure would induce more pronounced neuropathological changes in middle-aged rats. In addition, the gene expression pattern may vary depending on animal species, sex, specific tissue or even cell type, and thus individual areas of the brain undergo different patterns of age-related gene expression [Berchtold et al., 2008; Fraser et al., 2005; Ximerakis et al., 2019]. So far, most of the available data on genetic markers of brain aging comes from studies on cortex, cerebellum or hippocampus [Fraser et al., 2005; González-Velasco et al., 2020; Mohan et al., 2016; Weindruch et al., 2002]. In our study, the age-related genetic profile was evaluated in the hypothalamus because hypothalamic neurons are known to regulate neuroendocrine and autonomic nervous system control of energy balance, and mediate many responses to the nutritional deficit including CR [Dacks et al., 2013; Lizarbe et al., 2017]. Moreover, Lizarbe et al. [2017] have reported that HFD intake affects hypothalamic energy metabolism and leads to localized inflammatory state, astrocytosis, and microgliosis.

Previous studies have identified hundreds of genes differently expressed as organism ages, with those involved in stress response, inflammation, mitochondrial dysfunction or oxidative stress being consistently increased, and those related to tissue-specific functions being decreased [González-Velasco et al., 2020; Mohan et al., 2016; Zhou et al., 2012]. This is in line with our study as one of the major pathways differently expressed in HFD group was the inflammatory response (Table 3). It is well known that the brain undergoes numerous perturbations in inflammatory signaling during aging, and although it might be neuroprotective under some circumstances, generally it has been linked to the development of neuropathology and neuronal dysfunction [Berchtold et al., 2008; De Magalhães et al., 2009; Uranga et al., 2010]. The top downregulated gene in the HFD group was FCGBP which encodes the Fc fragment of the IgG-binding protein (Table 3). In this group, there was also the only significantly up-regulated gene - $\mathrm{CFH}$, acting as a negative regulator of the alternative pathway of the complement system [Noris $\&$ Remuzzi, 2013]. The upregulation of $C F H$ was also noted in the liver of rats fed HFD [Xie et al., 2010].

The other two top genes, GFAP and $S C N 2 B$, belong to the functional class of genes involved in neurodegeneration and synaptic transmission, while age-related abnormalities in synaptic functions are hypothesized to be a key event mediating cognitive decline [Mohan et al., 2016]. Moreover, neuronal GFAP gene expression, coding intermediate filament structural proteins and being a specific marker for mature astrocytes, is reported to show the highest correlation with the biological age [González-Velasco et al., 2020]. However, most of the studies reported increased expression of both GFAP and SCN2B in rodents' brain during aging [Boisvert et al., 2018; XiYang et al., 2016]. Therefore, the results obtained might suggest a specific molecular pathway of synaptic modification after HFD treatment.

Interestingly, the addition of RESV into HFD resulted in a major molecular shift in the rat hypothalamus (Table 3).
In the HFD+RESV group, a total of 50 genes (60\%) were identified as significantly underexpressed, and no gene overexpressed, when compared to the control group (Table 3). Among them, $42 \%(21 / 50)$ belong to inflammatory response pathways, while $12 \%$ each $(6 / 50)$ are involved in transcriptional regulation, proteostasis or DNA binding, 8\% (4/50) in laminopathies, and $6 \%$ each $(3 / 50)$ in neurodegeneration and synaptic transmission, mitochondrial dysfunction, genomic instability or telomere attrition. A large group of genes was significantly downregulated by more than 2-fold (32 genes) with $C 1 Q A, C 4 A, C D K N 1 C, C X 3 C L 1, G F A P$, and SCN2B displaying a $>3.5$-fold decrease in expression levels and $C X 3 C L 1$ being the top gene. Of the 50 genes significantly differentially expressed in the HFD+RESV group, 25 (50\%) exhibited expression changes in the same direction as in the HFD group (Table 3). Moreover, when compared to the HFD group, dietary supplementation with RESV caused a significant up-regulation of two genes associated with inflammatory response (CFHRl, LYZL1), and down-regulation of five genes, three of which could be assigned to inflammatory response, 1 to proteostasis, and 1 to cytoskeleton regulation (Table 4).

Barger et al. [2008] showed that RESV supplementation, similar to $\mathrm{CR}$, opposed most of the age-related transcriptional alterations in the aging heart of 30-month old mice. On the other hand, lesser effects on aging inhibition were obtained in skeletal muscle and neocortex. In our study, most of the down-regulated genes in the HFD+RESV group were identified to be critical for the activation of immune response and the induction of the complement components (CIQA, $C 1 Q C, c 1 S, C 3, C 4 A, C 4 B, C 5 A R 1)$. The overexpression of the complement system cascade is a common signature of aging and a trigger for the production of proinflammatory peptide fragments leading to neuronal damage [De Magalhães et al., 2009; Noris \& Remuzzi, 2013; Weindruch et al., 2002]. Therefore, decreased expression of complement cascade genes suggests that RESV, even when given with HFD, may beneficially influence markers of brain aging.

It is speculated that the neuroprotective action of RESV results mainly from the reduction of oxidative stress and neuroinflammation. Even though our data fit in part with this trend, it should be noted that RESV has pleiotropic properties and the ability to activate multiple signaling pathways [Baur et al., 2006; Lagouge et al., 2006]. Furthermore, it seems that the effects induced by RESV supplementation did not consist in inhibiting the negative effect of HFD, but on the contrary, elicited a completely different molecular response in the rat hypothalamus. This is confirmed by the fact that only $8 \%$ of the genes analyzed were significantly differentially expressed between HFD and HFD+RESV groups (Table 4), and yet significant differences were noted compared to the control group (Table 3). Another clue is that these minor changes in the metabolic response induced by the addition of RESV were sufficient to elicit an entirely different molecular response. Indeed, glucose or cholesterol metabolism (both parameters decreased in the HFD+RESV group) has been associated with brain aging and lifespan modulation [Dacks et al., 2013; Nuthikattu et al., 2019].

On the contrary, HFD supplementation with AKG remarkably attenuated aging-related changes in the hypothalamic 
TABLE 4. The hypothalamic gene expression profile associated with aging - part B.

\begin{tabular}{|c|c|c|c|c|}
\hline \multirow{2}{*}{ Gene symbol } & \multirow{2}{*}{ Gene name } & \multicolumn{3}{|c|}{ Fold change $^{1}$} \\
\hline & & HFD $v s$ HFD + RESV & HFD vs HFD+AKG & $\mathrm{HFD}+\mathrm{RESV} v_{s} \mathrm{HFD}+\mathrm{AKG}$ \\
\hline CFHRI & Complement component factor h-like 1 & $2.91(p=0.0108)$ & - & - \\
\hline$L Y Z L 1$ & Lysozyme-like 1 & $2.16(p=0.0108)$ & - & - \\
\hline$F C G B P$ & Fc fragment of $\operatorname{IgG}$ binding protein & - & $1.86(p=0.0214)$ & - \\
\hline ANXA5 & Annexin A5 & $-1.51(p=0.0176)$ & - & - \\
\hline$C l Q C$ & $\begin{array}{l}\text { Complement component } 1, \mathrm{q} \\
\text { subcomponent, } \mathrm{C} \text { chain }\end{array}$ & - & - & $-2.26(p=0.0434)$ \\
\hline$C l S$ & Complement component 1 , s subcomponent & - & - & $-2.27(p=0.0313)$ \\
\hline$C 3$ & Complement component 3 & - & - & $-1.91(p=0.0421)$ \\
\hline$C 4 A$ & $\begin{array}{l}\text { Complement component 4A } \\
\text { (Rodgers blood group) }\end{array}$ & - & - & $-3.06(p=0.0240)$ \\
\hline$C 4 B$ & Complement component 4B (Chido blood group) & - & - & $-2.08(p=0.0366)$ \\
\hline CXCL16 & Chemokine (C-X-C motif) ligand 16 & $-1.81(p=0.0297)$ & - & $-1.62(p=0.0334)$ \\
\hline PANXI & Pannexin 1 & $-1.83(p=0.0236)$ & - & $-1.83(p=0.0493)$ \\
\hline TOLLIP & Toll interacting protein & - & - & $-2.35(p=0.0437)$ \\
\hline$M B P$ & Myelin basic protein & - & - & $-1.71(p=0.0325)$ \\
\hline GFAP & Glial fibrillary acidic protein & - & $1.94(p=0.0397)$ & $-2.56(p=0.0180)$ \\
\hline$S C N 2 B$ & Sodium channel, voltage-gated, type II, beta & - & - & $-2.99(p=0.0182)$ \\
\hline PHF3 & PHD finger protein 3 & - & - & $-1.70(p=0.0348)$ \\
\hline SMAD2 & SMAD family member 2 & - & - & $-1.77(p=0.0109)$ \\
\hline ARIDIA & AT rich interactive domain $1 \mathrm{~A}$ (SWI-like) & - & - & $-1.92(p=0.0495)$ \\
\hline ELP3 & RCG52086-like & - & - & $-1.98(p=0.0269)$ \\
\hline FBXL16 & F-box and leucine-rich repeat protein 16 & - & - & $-2.52(p=0.0221)$ \\
\hline ARL6IP6 & ADP-ribosylation-like factor 6 interacting protein 6 & - & - & $-2.23(p=0.0244)$ \\
\hline JAKMIP3 & Janus kinase and microtubule interacting protein 3 & - & $1.59(p=0.0202)$ & $-1.84(p=0.0332)$ \\
\hline$R N F 144 B$ & Ring finger protein 144B & - & - & $-2.33(p=0.0147)$ \\
\hline TXNIP & Thioredoxin interacting protein & $-2.08(p=0.0231)$ & - & $-2.14(p=0.0400)$ \\
\hline$L M N A$ & Lamin A & - & - & $-1.75(p=0.0207)$ \\
\hline$L M N B I$ & Lamin B1 & - & $1.63(p=0.0224)$ & - \\
\hline$L M N B 2$ & Lamin B2 & - & $1.67(p=0.0496)$ & $-2.23(p=0.0382)$ \\
\hline COLIAl & Collagen, type I, alpha 1 & $-2.97(p=0.0132)$ & - & - \\
\hline EMLl & Echinoderm microtubule associated protein like 1 & - & $1.57(p=0.0223)$ & $-2.12(p=0.0176)$ \\
\hline$C D K N I C$ & Cyclin-dependent kinase inhibitor $1 \mathrm{C}$ & - & - & $-3.17(p=0.0448)$ \\
\hline
\end{tabular}

${ }^{1}$ Only genes whose expression differed significantly $(p \leq 0.05)$ with the fold regulation threshold of 1.5 are shown. Middle-aged rat fed for 6 weeks with high-fat diet (HFD), HFD supplemented with resveratrol (HFD+RESV), HFD supplemented with $\alpha$-ketoglutarate (HFD +AKG) or standard feed (control group - Control).

gene expression profile caused by HFD feeding, leading to a molecular response almost identical as in the control group (Table 3). In the HFD+AKG group, only one of the 84 genes surveyed - FCGBP - regulating neurodegeneration and synaptic transmission, was significantly downregulated compared to the control group, although a fold change tended to be lower compared with other groups (Table 3). When the gene expression profile was compared to the HFD group, AKG supplementation induced the significant overexpression of six genes (assigned to inflammatory response, neurodegeneration and synaptic transmission, proteostasis, laminopathies or cytoskeleton regulation) which represented 
$7 \%$ of the genes surveyed (Table 4). A large variation was also recorded between HFD+RESV and HFD + AKG groups (24 genes with significantly different expression levels) (Table 4).

Although the effect of AKG on brain aging is yet to be unraveled, it has been demonstrated that AKG has strong antioxidant activity and may prevent mitochondrial dysfunction and dyslipidemia in the brain [Thomas et al., 2015]. It is believed that by reducing oxidative stress and stimulating the production of cellular ATP, AKG may have a beneficial effect on brain performance and cognitive function; however, this effect has been described in terms of alleviating the symptoms of Alzheimer's disease, not normal brain aging [Thomas et al., 2015]. Additionally, Niemiec et al. [2011] have demonstrated that in older mice, AKG improves serum redox homeostasis to the level observed in young animals. Interestingly, the effect differed depending on AKG chemical structure, as its calcium salts reduced lipid peroxidation and enhanced total antioxidant capacity, while sodium salts modulated the activity of antioxidant enzymes [Niemiec et al., 2011]. Therefore, one can speculate that the ability of AKG to suppress the genetic effect of HFD feeding is due to its antioxidative properties. On the other hand, Chin et al. [2014] proved that AKG supplementation in the adult stage was sufficient for lifespan extension and delaying age-related phenotypes through the regulation of cellular energy metabolism and inhibition of ATP synthase and TOR function, suggesting a similar model to $\mathrm{CR}$.

\section{CONCLUSION}

Despite enormous efforts, our understanding of the ability of different dietary regimes to prevent or accelerate various aspects of brain aging is still relatively poor. Based on our study results, it is difficult to determine the exact relationship between plasma metabolic indicators and the molecular markers of brain aging. However, we proved that metabolic alterations induced by HFD consumption, such as high circulating glucose, insulin and lipids levels, might profoundly affect age-related markers in the middle-aged rats' hypothalamus, with the largest functional class being related to inflammatory response. Secondly, we showed that dietary RESV may ameliorate the metabolic changes induced by HFD feeding and cause a major molecular shift compared to HFD alone. In contrast, AKG supplementation did not affect the metabolic phenotype, but prevented the gene expression pattern caused by HFD consumption, mimicking the effects observed in the control group. Therefore, it seems that HFD-induced metabolic and genetic disturbances might be at least partially compensated with RESV or AKG supplementation, even though these compounds act in a different and specific manner. To sum up, our study demonstrated that nutritional intervention is a powerful approach to modulate molecular markers of brain aging, which in turn, may represent new diagnostic or therapeutic targets for optimizing the health span. Furthermore, in future studies, it could be interesting to look how different dietary conditions started at midlife would affect the metabolic and molecular responses in the individuals living in old age.

\section{RESEARCH FUNDING}

The authors received no specific funding for the study.

\section{CONFLICT OF INTERESTS}

The authors declare that there is no conflict of interest.

\section{ORCID IDs}

M. Oczkowicz https://orcid.org/0000-0001-8975-0200

S. Orczewska-Dudek https://orcid.org/0000-0001-6726-923X

M. Pieszka https://orcid.org/0000-0002-4342-2719

M. Pietras https://orcid.org/0000-0003-4683-9840

K. Ropka-Molik https://orcid.org/0000-0002-8555-0495

P. Szczurek-Janicka https://orcid.org/0000-0001-9008-3505

\section{REFERENCES}

1. Andersen, G., Burkon, A., Sulzmaier, F.J., Walker, J.M., Leckband, G., Fuhst, R., Erbersdobler, H.F., Somoza, V. (2011). High dose of dietary resveratrol enhances insulin sensitivity in healthy rats but does not lead to metabolite concentrations effective for SIRT1 expression. Molecular Nutrition \& Food Research, 55(8), 1197-1206. https://doi.org/10.1002/mnfr.201100292

2. Anderson, R.M., Weindruch, R. (2010). Metabolic reprogramming, caloric restriction and aging. Trends in Endocrinology \& Metabolism, 21(3), 134-141.

https://doi.org/10.1016/j.tem.2009.11.005

3. AOAC International. (2000). Official Methods of Analysis of the Association of Official Analytical Chemists. 17th ed. Gaithersburg, MD, USA.

4. Barger, J.L., Kayo, T., Vann, J.M., Arias, E.B., Wang, J., Hacker, T.A., Wang, Y., Raederstorff, D., Morrow, J.D., Leewenburgh, C., Allison, D.B., Saupe, K.W., Cartee, G.D., Weindruch, R., Prolla, T.A. (2008). A low dose of dietary resveratrol partially mimics caloric restriction and retards aging parameters in mice. PloS One, 3(6), art. no. e2264.

https://doi.org/10.1371/annotation/c54ef754-1962-4125-bf1976d3ec6f19e5

5. Baur, J.A., Pearson, K.J., Price, N.L., Jamieson, H.A., Lerin, C., Kalra, A., Prabhu, V.V., Allard, J.S., Lopez-Lluch, G., Lewis, K., Pistell, P.J., Poosala, S., Becker, K.G., Boss, O., Gwinn, D., Wang, M., Ramaswamy, S., Fishbein, K.W., Spencer, R.G., Lakatta, W.G., Le Couteur, D., Shaw, R.J., Navas, P., Puigserver, P., Ingram, D.K., de Cabo, R., Sinclair, D.A. (2006). Resveratrol improves health and survival of mice on a high-calorie diet. $\mathrm{Na}$ ture, 444, 337-342.

https://doi.org/10.1038/nature05354

6. Berchtold, N.C., Cribbs, D.H., Coleman, P.D., Rogers, J., Head, E., Kim, R., Beach, T., Miller, C., Troncoso, J., Trojanowski, J.Q., Zielke, R.H., Cotman, C.W. (2008). Gene expression changes in the course of normal brain aging are sexually dimorphic. Proceedings of National Academy of Sciences, 105(40), 15605-15610. https://doi.org/10.1073/pnas.0806883105

7. Boisvert, M.M., Erikson, G.A., Shokhirev, M.N., Allen, N.J. (2018). The aging astrocyte transcriptome from multiple regions of the mouse brain. Cell Reports, 22(1), 269-285.

https://doi.org/10.1016/j.celrep.2017.12.039 
8. Briggs, D.I., Lockie, S.H., Wu, Q., Lemus, M.B., Stark, R., Andrews, Z.B. (2013). Calorie-restricted weight loss reverses high-fat diet-induced ghrelin resistance, which contributes to rebound weight gain in a ghrelin-dependent manner. Endocrinology, 154(2), 709-717.

https://doi.org/10.1210/en.2012-1421

9. Chen, S., Bin, P., Ren, W., Gao, W., Liu, G., Yin, J., Duan, J., Li, Y., Yao, K., Huang, R., Tan, B., Yin, Y. (2017). Alpha-ketoglutarate (AKG) lowers body weight and affects intestinal innate immunity through influencing intestinal microbiota. Oncotarget, 8(24), art. no. 38184 .

https://doi.org/10.18632/oncotarget.17132

10. Cheserek, M.J., Wu, G., Li, L., Li, L., Karangwa, E., Shi, Y., Le, G. (2016). Cardioprotective effects of lipoic acid, quercetin and resveratrol on oxidative stress related to thyroid hormone alterations in long-term obesity. Journal of Nutritional Biochemistry, 33, 36-44.

https://doi.org/10.1016/j.jnutbio.2016.02.008

11. Chin, R.M., Fu, X., Pai, M.Y., Vergnes, L., Hwang, H., Deng, G., Diep, S., Lomenick, B., Meli, V.S., Monsalve, G.C., Hu, E., Whelan, S.A., Wang, J.X., Jung, G., Solis, G.M., Fazlollahi, F., Kaweeteerawat, C., Quach, A., Nili, M., Krall, A.S., Godwin, H.A., Chang, H.R., Faull, K.F., Guo, F., Jiang, M., Trauger, S.A., Saghatelian, A., Braas, D., Christofk, H.R., Clarke, C.F., Teitell, M.A., Petrascheck, M., Reue, K., Jung, M.E., Frand, A.R., Huang, J. (2014). The metabolite $\alpha$-ketoglutarate extends lifespan by inhibiting ATP synthase and TOR. Nature, 510(7505), 397-401. https://doi.org/10.1038/nature13264

12. Cho, S.J., Jung, U.J., Choi, M.S. (2012). Differential effects of low-dose resveratrol on adiposity and hepatic steatosis in diet-induced obese mice. British Journal of Nutrition, 108(12), 2166-2175.

https://doi.org/10.1017/S0007114512000347

13. Dacks, P.A., Moreno, C.L., Kim, E.S., Marcellino, B.K., Mobbs, C.V. (2013). Role of the hypothalamus in mediating protective effects of dietary restriction during aging. Frontiers in Neuroendocrinology, 34(2), 95-106.

https://doi.org/10.1016/j.yfrne.2012.12.001

14. Dąbek, M., Kruszewska, D., Filip, R., Hotowy, A., Pierzynowski, Ł., Wojtasz-Pająk, A., Szymanczyk, S., Valverdre-Piedra, J.L., Werpachowska. E., Pierzynowski, S.G. (2005). $\alpha$-Ketoglutarate (AKG) absorption from pig intestine and plasma pharmacokinetics. Journal of animal physiology and animal nutrition, 89(11-12), 419-426.

https://doi.org/10.1111/j.1439-0396.2005.00566.x

15. De Magalhães, J.P., Curado, J., Church, G.M. (2009). Meta-analysis of age-related gene expression profiles identifies common signatures of aging. Bioinformatics, 25(7), 875-881. https://doi.org/10.1093/bioinformatics/btp073

16. Franco, J.G., Dias-Rocha, C.P., Fernandes, T.P., Maia, L.A., Lisboa, P.C., Moura, E.G., Pazos-Moura, C.C., Trevenzoli, I.H. (2016). Resveratrol treatment rescues hyperleptinemia and improves hypothalamic leptin signaling programmed by maternal high-fat diet in rats. European Journal of Nutrition, 55(2), 601-610. https://doi.org/10.1007/s00394-015-0880-7

17. Fraser, H.B., Khaitovich, P., Plotkin, J.B., Pääbo, S., Eisen, M.B. (2005). Aging and gene expression in the primate brain. PLoS Biology, 3(9), art. no. e274.

https://doi.org/10.1371/journal.pbio.0030274
18. González-Velasco, O., Papy-García, D., Le Douaron, G., Sánchez-Santos, J.M., De Las Rivas, J. (2020). Transcriptomic landscape, gene signatures and regulatory profile of aging in the human brain. Biochimica et Biophysica Acta - Gene Regulatory Mechanisms, 1863(6), art no. 194491.

https://doi.org/10.1016/j.bbagrm.2020.194491

19. Jimoh, A., Tanko, Y., Ayo, J.O., Ahmed, A., Mohammed, A. (2018). Resveratrol increases serum adiponectin level and decreases leptin and insulin level in an experimental model of hypercholesterolemia. Pathophysiology, 25(4), 411-417.

https://doi.org/10.1016/j. pathophys.2018.08.005

20. Kandhare, A.D., Bandyopadhyay, D., Thakurdesai, P.A. (2018). Low molecular weight galactomannans-based standardized fenugreek seed extract ameliorates high-fat diet-induced obesity in mice via modulation of FASn, IL-6, leptin, and TRIP-Br2. RSC Advances, 8(57), 32401-32416.

https://doi.org/10.1039/C8RA05204B

21. Lagouge, M., Argmann, C., Gerhart-Hines, Z., Meziane, H., Lerin, C., Daussin, F., Messadeq, N., Milne, J., Lambert, P., Elliott, P., Geny, B., Laakso, M., Puigserver, P., Auwex, J. (2006). Resveratrol improves mitochondrial function and protects against metabolic disease by activating SIRT1 and PGC-1alpha. Cell, 127, 1109-1122. https://doi.org/10.1016/j.cell.2006.11.013

22. Lizarbe, B., Cherix, A., Duarte, J.M., Cardinaux, J.R., Gruetter, R. (2019). High-fat diet consumption alters energy metabolism in the mouse hypothalamus. International Journal of Obesity, 43(6), 1295-1304. https://doi.org/10.1038/s41366-018-0224-9

23. Miura, D., Miura, Y., Yagasaki, K. (2003). Hypolipidemic action of dietary resveratrol, a phytoalexin in grapes and red wine, in hepatoma-bearing rats. Life Science, 73(11), 1393-1400. https://doi.org/10.1016/S0024-3205(03)00469-7

24. Mohamed, I.A., Zaki, N.A., Walaa, A.M. (2010). Alterations in insulin, leptin, orexin-A and neuropeptide-Y levels in the high-fat diet fed rats. Australian Journal of Basic and Applied Sciences, 4(6), 1473-1481.

25. Mohan, A., Mather, K.A., Thalamuthu, A., Baune, B.T., Sachdev, P.S. (2016). Gene expression in the aging human brain: an overview. Current Opinion in Psychiatry, 29(2), 159-167. https://doi.org/10.1097/YCO.0000000000000238

26. Morrison, C.D., Pistell, P.J., Ingram, D.K., Johnson, W.D., Liu, Y., Fernandez-Kim, S.O., White, C.L., Purpera, M.N., Uranga, R.M., Bruce-Keller, A.J., Keller, J.N. (2010). High fat diet increases hippocampal oxidative stress and cognitive impairment in aged mice: implications for decreased Nrf2 signaling. Journal of Neurochemistry, 114(6), 1581-1589.

https://doi.org/10.1111/j.1471-4159.2010.06865.x

27. Müller, R.H., Radtke, M., Wissing, S.A. (2002). Nanostructured lipid matrices for improved microencapsulation of drugs. International Journal of Pharmaceutics, 242(1-2), 121-128. https://doi.org/10.1016/S0378-5173(02)00180-1

28. Niemiec, T., Sikorska, J., Harrison, A., Szmidt, M., Sawosz, E., Wirth-Dzieciolowska, E., Wilczak, J., Pierzynowski, S. (2011). Alpha-ketoglutarate stabilizes redox homeostasis and improves arterial elasticity in aged mice. Journal of Physiology and Pharmacology, 62(1), art. no. 37.

29. Noris, M., Remuzzi, G. (2013). Overview of complement activation and regulation. Seminars in Nephrology, 33(6), 479-492.

https://doi.org/10.1016/j.semnephrol.2013.08.001 
30. NRC. (1995). Nutrient requirement of laboratory animals. In: National Research Council (US) Subcommittee on Laboratory Animal Nutrition. National Academies Press (US), Washington (DC), USA

31. Nuthikattu, S., Milenkovic, D., Rutledge, J., Villablanca, A. (2019). The western diet regulates hippocampal microvascular gene expression: an integrated genomic analyses in female mice. Scientific Reports, 9(1), art. no. 19058.

https://doi.org/10.1038/s41598-019-55533-9

32. Radzki, R.P., Bienko, M., Pierzynowski, S.G. (2009). Effect of dietary alpha-ketoglutarate on blood lipid profile during hypercholesterolaemia in rats. Scandinavian Journal of Clinical and Laboratory Investigation, 69(2), 175-180.

https://doi.org/10.1080/00365510802464633

33. Salminen, A., Kaarniranta, K., Hiltunen, M., Kauppinen, A. (2014). Krebs cycle dysfunction shapes epigenetic landscape of chromatin: Novel insights into mitochondrial regulation of aging process. Cell Signal, 26(7), 1598-1603.

https://doi.org/10.1016/j.cellsig.2014.03.030

34. Testa, G., Biasi, F., Poli, G., Chiarpotto, E. (2014). Calorie restriction and dietary restriction mimetics: a strategy for improving healthy aging and longevity. Current Pharmaceutical Design, 20(18), 2950-2977.

https://doi.org/10.2174/13816128113196660699

35. Tian, Q., Zhao, J., Yang, Q., Wang, B., Deavila, J.M., Zhu, M.J., Du, M. (2020). Dietary alpha-ketoglutarate promotes beige adipogenesis and prevents obesity in middle-aged mice. Aging Cell, 19(1), art. no. e13059.

https://doi.org/10.1111/acel.13059

36. Thomas, S.C., Alhasawi, A., Appanna, V.P., Auger, C., Appanna, V.D. (2015). Brain metabolism and Alzheimer's disease: The prospect of a metabolite-based therapy. Journal of Nutrition, Health and Aging, 19(1), 58-63. https://doi.org/10.1007/s12603-014-0511-7

37. Uranga, R.M., Bruce-Keller, A.J., Morrison, C.D., Fernandez-Kim, S.O., Ebenezer, P.J., Zhang, L., Dasuri, K., Keller, J.N. (2010). Intersection between metabolic dysfunction, high fat diet consumption, and brain aging. Journal of Neurochemistry, 114, 344-361. https://doi.org/10.1111/j.1471-4159.2010.06803.x

38. Walle, T., Hsieh, F., DeLegge, M.H., Oatis, J.E., Walle, U.K. (2004). High absorption but very low bioavailability of oral resveratrol in humans. Drug Metabolism \& Disposition, 32(12), 1377-1382.

https://doi.org/10.1124/dmd.104.000885

39. Weindruch, R., Kayo, T., Lee, C.K., Prolla, T.A. (2002). Gene expression profiling of aging using DNA microarrays. Mechanisms of Ageing and Development, 123(2-3), 177-193.

https://doi.org/10.1016/S0047-6374(01)00344-X

40. Xie, Z., Li, H., Wang, K., Lin, J., Wang, Q., Zhao, G., Jia, W., Zhang, Q. (2010). Analysis of transcriptome and metabolome profiles alterations in fatty liver induced by high-fat diet in rat. Metabolism, 59(4), 554-560.

https://doi.org/10.1016/j.metabol.2009.08.022

41. Ximerakis, M., Lipnick, S.L., Innes, B.T., Simmons, S.K., Adiconis, X., Dionne, DMayweather, B.A., Nguyen, L., Niziolek, Z., Ozek, C., Butty, V.L., Isserlin, R., Buchanan, S.M., Levine, S.S., Regev, A., Bader, G.D., Levin, J.Z., Rubin, L.L. (2019). Single-cell transcriptomic profiling of the aging mouse brain. Nature Neuroscience, 22(10), 1696-1708. https://doi.org/10.1038/s41593-019-0491-3

42. XiYang, Y.B., Wang, Y.C., Zhao, Y., Ru, J., Lu, B.T., Zhang, Y.N., Wang, N.C., Hu, W.Y., Liu, J., Yang, J.W., Wang, Z.J., Hao, C.G., Feng, Z.T., Xiao, Z.C., Dong, W., Quan, X.Z., Zhang, L.F., Wang, T.H. (2016). Sodium channel voltage-gated beta 2 plays a vital role in brain aging associated with synaptic plasticity and expression of COX5A and FGF-2. Molecular Neurobiology, 53(2), 955-967. https://doi.org/10.1007/s12035-014-9048-3

43. Zahn, J.M., Poosala, S., Owen, A.B., Ingram, D.K., Lustig, A., Carter, A., Weeraratna, A.T., Taub, D.D., Gorospe, M., Mazan-Mamczarz, K., Lakatta, E.G., Boheler, K.R., Xu, X., Mattson, M.P., Falco, G., Ko, M.S., Schlessinger, D., Firman, J., Kummerfeld, S.K., Wood, W.H., Zonderman, A.B., Kim, S.K., Becker, K.G. (2007). AGEMAP: a gene expression database for aging in mice. PLoS Genetics, 3(11), art. no. e201.

https://doi.org/10.1371/journal.pgen.0030201

44. Zhou, B., Yang, L., Li, S., Huang, J., Chen, H., Hou, L., Wang, J., Green, C.D., Yan, Z., Huang, X., Kaeberein, M., Zhu, L., Xiao, H., Liu, Y., Han, J.D. (2012). Midlife gene expressions identify modulators of aging through dietary interventions. Proceedings of the National Academy of Sciences USA, 109(19), E1201-E1209. https://doi.org/10.1073/pnas.1119304109 